Article

\title{
Experimental Evaluation of the Role of Ecologically-Relevant Hosts and Vectors in Japanese Encephalitis Virus Genotype Displacement
}

\author{
Ajit K. Karna ${ }^{1}(\mathbb{D})$ and Richard A. Bowen ${ }^{1,2, *}$ \\ 1 Department of Microbiology, Immunology, and Pathology, Colorado State University, Fort Collins, \\ CO 80523, USA; ajit.karna@gmail.com \\ 2 Department of Biomedical Sciences, Colorado State University, Fort Collins, CO 80523, USA \\ * Correspondence: Richard.Bowen@Colostate.Edu; Tel.: +1-970-491-5768
}

Received: 1 December 2018; Accepted: 4 January 2019; Published: 6 January 2019

check for updates

\begin{abstract}
Japanese encephalitis virus (JEV) is a flavivirus that is maintained via transmission between Culex spp. mosquitoes and water birds across a large swath of southern Asia and northern Australia. Currently JEV is the leading cause of vaccine-preventable encephalitis in humans in Asia. Five genotypes of JEV (G-I-G-V) have been responsible for historical and current outbreaks in endemic regions, and G-I and G-III co-circulate throughout Southern Asia. While G-III has historically been the dominant genotype worldwide, G-I has gradually but steadily displaced G-III. The objective of this study was to better understand the phenomenon of genotype displacement for JEV by evaluating both avian host and mosquito vector susceptibilities to infection with representatives from both G-I and G-III. Since ducks and Culex quinquefasciatus mosquitoes are prevalent avian hosts and vectors perpetuating JEV transmission in JE endemic areas, experimental evaluation of virus replication in these species was considered to approximate the natural conditions necessary for studying the role of host, vectors and viral fitness in the JEV genotype displacement context. We evaluated viremia in ducklings infected with G-I and G-III, and did not detect differences in magnitude or duration of viremia. Testing the same viruses in mosquitoes revealed that the rates of infection, dissemination and transmission were higher in virus strains belonging to G-I than G-III, and that the extrinsic incubation period was shorter for the G-I strains. These data suggest that the characteristics of JEV infection of mosquitoes but not of ducklings, may have play a role in genotype displacement.
\end{abstract}

Keywords: Japanese encephalitis virus; duck; Culex quinquefasciatus; genotype displacement; host competence; vector competence; Asia

\section{Introduction}

Japanese encephalitis virus (JEV) belongs to the family Flaviviridae and genus Flavivirus, and is an enveloped, single-stranded positive-sense RNA virus having a genome approximately $11 \mathrm{~kb}$ in size [1,2]. JEV exists in an enzootic transmission cycle in which the infectious Culicine mosquito, primarily Culex tritaeniorhynchus, transmits the virus via bite to ardeid birds such as herons and egrets (reservoir hosts) and pigs (amplifying host) [3,4]. The mosquito-bird and the mosquito-pig cycles are independent of each other, and humans are incidental hosts in either transmission cycle [3-5]. This zoonotic virus is neuroinvasive and neurovirulent in humans and, although it causes substantial morbidity among all unvaccinated age groups, mortality is seen predominantly in children [6,7]. JEV is the leading cause of arboviral encephalitis in the world and is common in regions where paddy fields, pig husbandry, and mosquitoes co-exist $[6,8]$. With an estimated three billion people living in currently known at-risk areas globally, the challenge remains in non-JEV endemic areas 
where the known JEV-vectors have been reported. Moreover, the possibility exists for introduction of JEV into areas in Africa, Europe, and the Middle East where populations of competent mosquito vectors have been reported [6,8-10]. An effective vaccine for use in humans is commercially available, yet 50,000-60,000 cases of Japanese encephalitis (JE) are reported annually worldwide, largely because of the shortfalls in vaccine supply and the cost of vaccine itself $[4,6,11,12]$.

Japanese encephalitis virus is thought to have emerged from ancestral viruses during the 19th century in the region of the Malay [6]. Historical descriptions of human illness having clinical manifestations compatible with JE suggest infections occurring as early as 1871 [6,12]. The first definitive report of JEV outbreaks dates to 1924, when an outbreak occurred in Japan [6,13]. Five genetic subtypes of JEV, referred to as genotypes, have been defined based on phylogenetic analysis of nucleotide sequence of the envelope protein gene and designated G-I through G-V [14-16]. Viruses from each genotype have been responsible for historical and current outbreaks in humans and other animals in endemic regions since its emergence $[6,12,13,17]$. JEV of different genotypes can be distinguished antigenically $[7,18,19]$, and it is thought that effective cross-genotype immune protection is conferred by infection with viruses belonging to anyone of G-I, G-II, G-III or G-IV viruses [7]. At present, there is no data on cross-genotype protection information for G-V. Although currently available vaccines based on G-III protect against G-I infection, the protection may be sub-optimal [7,20-23], suggesting that displacement of G-III by G-I may adversely affect current vaccine effectiveness. The occurrence of genomic variation between genotypes has been thought to enable one genotype of JEV to become more fit than the other one in the ecological niches in which they circulate $[9,13,24-27]$. Competitive displacement among JEV genotypes has been previously observed including complete or partial displacement of G-III by G-I strains in Asia [27-31] and G-II by G-I strains in Australia [9,13,24-26,28]. G-III strains were dominant between 1935 and 1990, but G-I strains began to appear in Indonesia, Thailand and Cambodia in the 1970s and gradually became dominant in most parts of Asia. Although differences in virulence and neuro-invasiveness were not identified [7,31], G-I dominated over other JEV genotypes in Japan, Korea, Thailand, Taiwan and Vietnam [30,31]. Co-circulation and genotype/strain displacement are common phenomenon among flaviviruses. It was observed with West Nile virus (WNV), a closely related flavivirus, when the WNV-02 genotype displaced the WNV-NY99 genotype in the USA [32,33]. Among other well-studied examples, the endemic American genotype of dengue virus type-2 (DENV-2) was displaced by the Southeast Asian genotype of DENV-2 [34] and a native DENV-3 strain was displaced by an invasive DENV-3 strain in Sri Lanka in the 1980s [35]. Similarly, the DENV-2 Asian-American genotype NI-1 clade was replaced by the NI-2B clade in Nicaragua [36]. Such displacements have several potential impacts on the international public health infrastructure, including the possibility that currently available vaccines are sub-optimal and that future displacement events could perhaps jeopardize current vaccination programs.

The mechanisms responsible for dominance of G-I strains and displacement of G-III strains remains poorly understood. Studies based on nucleotide sequence analysis have described genetic diversity, evolutionary history, and host composition over the course of genotype displacement $[13,26,37]$. Studies based on surveillance of vectors and hosts have demonstrated frequent introductions of G-I strains in areas previously dominated by G-III strains $[25,27,28,38,39]$. A study by Schuh et al., [28] used cultured cell-based (Aedes albopictus C6/36 cells and duck embryo fibroblasts) approaches to explain the JEV genotype displacement and found that JEV G-I isolates indicated significantly higher infectivity titer than JEV G-III isolates at 24, 36, and 48-hour post-infection in C6/36 cells. Another study tested susceptibilities of $C x$. quinquefasciatus to JEV G-I and G-III strains, and found North American $C x$. quinquefasciatus as a competent vector for JEV G-I and G-III strains but JEV G-III demonstrated significantly higher infection rate than JEV G-I and non-demonstrable difference in transmission rate between both genotypes [40]. However, this latter study [40] incorporated only a single isolate of G-III and two isolates of G-I, limiting the inferences that could be drawn and did not address infection in vertebrate hosts. What has been lacking in previous attempts to explain JEV genotype displacement is 
evaluation of ecologically relevant avian hosts and mosquito vectors with the same strains of virus. Due to continued evolution, JEV remains as an emerging worldwide human health threat and disease severity within the human population could be increased by an emergence of new genotypes with altered disease manifestations, transmission potential, or resistance to current vaccines. The study presented here used hosts and the vectors involved in natural JEV ecology, and was designed to enhance our understanding of JEV genotype displacement with the hypothesis that JEV G-I has an enhanced ability to replicate in mosquitoes and/or avian hosts relative to JEV G-III.

\section{Materials and Methods}

\subsection{Ethics Statement}

The study was approved by the Animal Care and Use Committee of Colorado State University (protocol number: 16-6477A) and was conducted in biosafety level-3 facility approved by the Association for the Assessment and Accreditation of Laboratory Animal Care, International (AAALAC).

\subsection{Cells and Viruses}

Vero (African green monkey kidney epithelial) cells, a mammalian cell type that does not possess functional interferon signaling, obtained from the American Type Culture Collection (Manassas, VA, USA) were maintained in Dulbecco's modified Eagle's medium (DMEM) containing 5\% bovine calf serum (BCS), penicillin $(100 \mathrm{U} / \mathrm{mL})$ and streptomycin $(50 \mu \mathrm{g} / \mathrm{mL})$ at $37^{\circ} \mathrm{C}$ with $5 \% \mathrm{CO}_{2}$. Stock viruses were inoculated in Vero cells and fresh viruses were harvested at the end of 4 days post-inoculation (dpi). The strains of JEV utilized in this study are described in Table 1. All virus strains were titrated by double-overlay plaque assay in Vero cells using techniques previously described [41].

Table 1. Japanese encephalitis viruses utilized in the study.

\begin{tabular}{|c|c|c|c|c|c|}
\hline $\begin{array}{l}\text { Virus Strain } \\
\text { (Genotype) }\end{array}$ & Source & $\begin{array}{c}\text { Collection } \\
\text { Year }\end{array}$ & $\begin{array}{l}\text { Passage } \\
\text { History }\end{array}$ & $\begin{array}{l}\text { Country } \\
\text { (Climate) }\end{array}$ & $\begin{array}{c}\text { GenBank } \\
\text { Accession \# }\end{array}$ \\
\hline $\begin{array}{c}\text { KE-093-83 } \\
(\mathrm{G}-\mathrm{I})\end{array}$ & Mosquito & 1983 & Vero\#1 & $\begin{array}{l}\text { Thailand } \\
\text { (Tropical) }\end{array}$ & KF192510 \\
\hline $\begin{array}{l}\text { MAR864 } \\
\text { (G-I) }\end{array}$ & Cx. tritaeniorhynchus & 1967 & $\begin{array}{c}\text { C6/36\#1, } \\
\text { Vero\#1 }\end{array}$ & $\begin{array}{l}\text { Cambodia } \\
\text { (Tropical) }\end{array}$ & D00983 \\
\hline $\begin{array}{l}\text { JE-91 } \\
(\mathrm{G}-\mathrm{I})\end{array}$ & Cx. tritaeniorhynchus & 1991 & $\begin{array}{c}\text { C6/36\#1, } \\
\text { Vero\#1 }\end{array}$ & $\begin{array}{c}\text { Korea } \\
\text { (Temperate) }\end{array}$ & GQ415355 \\
\hline $\begin{array}{l}\text { CH392 } \\
\text { (G-III) }\end{array}$ & Cx. tritaeniorhynchus & 1987 & $\begin{array}{c}\text { Vero\#1, } \\
\text { C6/36\#2 }\end{array}$ & $\begin{array}{c}\text { Taiwan } \\
\text { (Sub-tropical) }\end{array}$ & U44961 \\
\hline $\begin{array}{c}\text { JKT27-087 } \\
\text { (GIII) }\end{array}$ & Mosquito & 1987 & C6/36\#1 & $\begin{array}{l}\text { Indonesia } \\
\text { (Tropical) }\end{array}$ & JQ429308 \\
\hline $\begin{array}{l}\text { Sagiyama } \\
\text { (G-III) }\end{array}$ & Cx. tritaeniorhynchus & 1957 & C6/36\#1 & $\begin{array}{c}\text { Japan } \\
\text { (Temperate) }\end{array}$ & D00972 \\
\hline
\end{tabular}

\subsection{In Vitro Growth Curve Kinetics}

Five replicates of a multi-step growth curve in Vero cells were obtained for all six viruses using a multiplicity of infection (MOI) of 0.01. Briefly, after inoculating the cells with viruses, the plates were incubated for $2 \mathrm{~h}$ at $37^{\circ} \mathrm{C}$ with $5 \% \mathrm{CO}_{2}$, virus inoculum was removed, cells were washed once with PBS and $5 \mathrm{~mL}$ fresh growth media (DMEM with 5\% FBS) was added. Samples for virus titration were collected on the day of inoculation (0-day post-inoculation, dpi), and daily for 8 days; at each sampling, $0.5 \mathrm{~mL}$ of supernatant was harvested and replaced with the same amount of fresh growth media. The supernatants were supplemented with $0.1 \mathrm{~mL}$ FBS and stored at $-80^{\circ} \mathrm{C}$ until assayed by plaque assay in Vero cells. 


\subsection{Animal Experiments}

Indian runner ducks (Anas platyrhynchos domesticus obtained from Murray McMurray Hatchery, Webster City, IA, USA) were housed under biosafety level-3 containment. Thirty ducklings were randomly allocated to six groups, corresponding to the six virus strains to be tested. Ducklings were banded with their specific numbers assigned to them. One extra duckling was added to either groups inoculated with MAR864 and Sagiyama strains, but was not inoculated and served as contact control. The duckling-cages were kept away from each other to prevent any contacts between groups. The ducklings were fed standard waterfowl feed and had water available ad libitum. The ducklings were inoculated subcutaneously with $\sim 10^{6} \mathrm{PFU}$ of each virus at 5 to 6 days of age. A $100 \mu \mathrm{L}$ blood sample was withdrawn from each duckling daily and immediately diluted into $450 \mu \mathrm{L}$ of BA-1 medium (DMEM containing $1 \%$ bovine serum albumin, $250 \mathrm{mg} / \mathrm{L}$ sodium bicarbonate, gentamicin $(50 \mathrm{mg} / \mathrm{L}$ ), penicillin (100,000 IU/L) and streptomycin $(50 \mathrm{mg} / \mathrm{L})$ ) yielding a serum dilution of approximately 1:10. Body temperature and weight were measured three times at a single time-point and average measurement was recorded daily from the day before inoculation through $7 \mathrm{dpi}$ and on 10, 14, and 21 dpi. Oral and cloacal swab samples were taken on 3, 4 and 5 dpi and immediately added to $450 \mu \mathrm{L}$ of BA-1 medium supplemented with amphotericin B $(2.5 \mathrm{mg} / \mathrm{L})$, polymyxin B $(50,000 \mathrm{U} / \mathrm{L})$. and twice the standard concentration of penicillin, streptomycin, gentamicin. The samples were immediately stored at $-80^{\circ} \mathrm{C}$ until assay. All ducklings were euthanized on $21 \mathrm{dpi}$.

\subsection{Mosquito Experiments}

Culex quinquefasciatus Say mosquitoes were obtained from a colony maintained at the Arthropod-borne and Infectious Diseases Laboratory at Colorado State University. This colony was established using mosquitoes collected in Sebring County, Florida in 1988. Larvae of the mosquitoes were provided with powdered fish food (Walmart, Fort Collins, CO, USA), and when pupae started emerging, they were transferred in a cup with water inside a container covered with a mesh. The insectary was maintained at $26-27^{\circ} \mathrm{C}, 16: 8$ light: dark cycle, and $70-80 \%$ relative humidity. Female mosquitoes of the F11-F13 generations (5-7 days post-eclosion) were used in this study.

\subsection{Vector Competence and Extrinsic Incubation Period}

Vero cells cultured in $25 \mathrm{~cm}^{2}$ flasks were inoculated with each of the six strains of JEV G-I and G-III at an MOI of 0.01. Four days later, the supernatant from each flask was collected, centrifuged $\left(10,000 \times g\right.$ for $8 \mathrm{~min}$ at $\left.4{ }^{\circ} \mathrm{C}\right)$ to remove cellular debris, and the fresh, clarified supernatants were used for feeding mosquitoes. Mosquitoes were fed with defibrinated cattle blood mixed with freshly harvested viruses at a 1:1 ratio that was titrated at the time of use by plaque assay in Vero cells. The blood-virus mixture was pipetted into the loading chamber of a Hemotek membrane feeding system (Hemotek, UK) covered with pork casing (Whole Foods Market, Fort Collins, CO, USA), and the mosquitoes were allowed to feed for $1 \mathrm{~h}$ at ambient room condition at $26^{\circ} \mathrm{C}$ and $80 \%$ relative humidity. Blood-engorged mosquitoes for each virus strain were briefly cold anesthetized $\left(4{ }^{\circ} \mathrm{C}\right)$ and separated into two groups for assay at day 7 and 14 post-feeding (dpf). The blood-engorged mosquitoes were incubated at $26^{\circ} \mathrm{C}$ and $70 \%$ relative humidity with ad libitum water and sugar cubes. On 7 and $14 \mathrm{dpf}, 60$ mosquitoes per virus strain were cold anesthetized $\left(4^{\circ} \mathrm{C}\right)$, and legs and wings were removed and transferred into a clean tube containing two stainless steel beads and $250 \mu \mathrm{L}$ mosquito diluent (PBS supplemented with 20\% heat-inactivated FBS and antibiotics (100 mg/L gentamicin, $200 \mathrm{IU} / \mathrm{L}$ penicillin $\mathrm{G}, 100 \mathrm{mg} / \mathrm{L}$ streptomycin, and $5 \mathrm{mg} / \mathrm{L}$ amphotericin $\mathrm{B})$ ). The mosquito bodies were placed with their proboscis inserted in a capillary tube containing immersion oil (about $5 \mu \mathrm{L}$ ) for at least $30 \mathrm{~min}$. After salivation, mosquito bodies were transferred into a separate tube with mosquito diluent and beads. The ends of capillary tubes containing immersion oil and saliva were broken off into micro centrifuge tubes containing $100 \mu \mathrm{L}$ mosquito diluent. Mosquito tissues (bodies, and legs + wings) were homogenized at 25 cycles/second for $1 \mathrm{~min}$ in a mixer mill and subsequently 
centrifuged at $15,000 \times g$ for $3 \mathrm{~min}$ at $4^{\circ} \mathrm{C}$. To determine the infection status of mosquito tissues and saliva, $50 \mu \mathrm{L}$ of each sample was inoculated onto Vero cell monolayers in two replicate wells of a 96-well plate and incubated at $37^{\circ} \mathrm{C}$. After incubation for an hour, $150 \mu \mathrm{L}$ of DMEM supplemented with $10 \%$ FBS was added into each well and the plates were incubated for $24 \mathrm{~h}$ at $37^{\circ} \mathrm{C}$. Media from the 96-well plates inoculated with mosquito samples was decanted at $24 \mathrm{~h}$; cells were washed once with PBS, fixed with $70 \%$ acetone for $1 \mathrm{~h}$ and dried. The cells were stained by addition of $50 \mu \mathrm{L}$ of diluted mouse anti-JEV hyper-immune ascitic fluid (Source: Centers for Disease Control and Prevention, Fort Collins) (1:100 in PBS) for $1 \mathrm{~h}$ at $37^{\circ} \mathrm{C}$, washed in PBS, then incubated for $1 \mathrm{~h}$ with $50 \mu \mathrm{L}$ of DyLight conjugate of Goat anti-Mouse Ig (H + L, 1:100 in PBS) (ThermoFisher Scientific, Waltham, MA, USA). The plates were washed again with PBS and observed under a fluorescent microscope. The sample was determined positive if replicate wells demonstrated fluorescence and negative if none of the wells demonstrate fluorescence. Controls in each assay consisted of duplicate wells inoculated with BA-1 diluent or BA-1 spiked with stock JEV. The infection rate was determined as the proportion of mosquito bodies that were found infected to the total number of mosquitoes exposed to the infectious blood meal. Dissemination rate was determined as the proportion of mosquito legs and wings that were found infected to the total number of mosquitoes exposed to the infectious blood meal. Similarly, transmission rate was determined as the proportion of mosquito saliva samples that were found infected to the total number of mosquitos exposed to the infectious blood meal.

\subsection{Virus Titration and Serology}

Replication of JEV in ducklings was measured as viremia titer. Plaques were counted on one and two days after the second overlay, and viremia titers were expressed as plaque forming units (PFU)/mL. The minimum concentration of JEV in serum or swab samples that could be detected using this assay was set at $\sim 100 \mathrm{PFU} / \mathrm{mL}$. Neutralizing antibody titers in sera were determined by plaque reduction neutralization test (PRNT). Briefly, 2-fold serial dilutions (starting at $1: 10)$ of heat-inactivated $\left(56^{\circ} \mathrm{C}\right.$ for $30 \mathrm{~min}$ ) duckling sera were mixed with equal volumes of stock virus (JEV VN strain, genotype I) diluted to $200 \mathrm{PFU} / \mathrm{mL}$. After $1 \mathrm{~h}$ of incubation, the serum-virus mixtures were inoculated into wells in 6-well plates of confluent Vero cells and processed subsequently as described for plaque assay. Plaques were counted one day after the second overlay and neutralization titer was expressed as the reciprocal of the highest dilution of the serum that inhibited $\geq 90 \%$ of JEV plaques $\left(\mathrm{PRNT}_{90}\right)$.

\subsection{Data Analysis}

Virus titer in Vero cells culture and viremia titer in ducklings were expressed as mean $( \pm 1 \mathrm{SE})$. The mean peak virus titer of each of the six JEV strains inoculated in Vero cells were compared using one-way ANOVA, and the time x strain interaction was analyzed by repeated measures ANOVA. Similarly, the mean peak viremia titers of the six strains in ducklings were compared using one-way ANOVA. Furthermore, infection and dissemination percentages were arcsine-square root transformed to render them normal, normality was checked on transformed data and compared by standard least squares method between G-I and G-III in the mosquito study. Since the data on transmission proportions cannot be normally distributed, as $50 \%$ of the values are tied 0 's, transmission proportions for G-I on $7 \mathrm{dpf}$, G-III on $7 \mathrm{dpf}$, G-I on $14 \mathrm{dpf}$ and G-III on $14 \mathrm{dpf}$ were pooled and compared by Fisher's exact test. SAS 9.4 (SAS Institute, Cary, NC, USA) was used for all statistical analysis. Graphs were made on GraphPad Prism 7.0 (La Jolla, CA, USA). The statistical significance was declared at $p<0.05$. 


\section{Results}

\subsection{In Vitro Growth Kinetics}

The growth kinetics of all six strains of JEV were comparable in Vero cells (Figure 1). Five of the viruses reached a peak titer on $2 \mathrm{dpi}\left(\mathrm{mean} \pm 1 \mathrm{SE}, \log _{10} \mathrm{PFU} / \mathrm{mL}\right.$ ): KE-093-83 (8.6 \pm 0.3 ), MAR864 $(8.5 \pm 0.2)$, JE-91 $(8.8 \pm 0.1)$, CH392 $(9.0 \pm 0.04)$, and Sagiyama $(8.7 \pm 0.2)$. The JKT27-087 virus achieved peak titer on $3 \mathrm{dpi}(8.1 \pm 0.3)$. When comparing only the mean peak virus titer $(2 \mathrm{dpi})$, one-way ANOVA revealed a significant difference in the peak virus titer among strains $\left(\mathrm{F}_{5}=8.9\right.$, $p<0.0001$ ), and Tukey-Kramer post-hoc analysis indicated that the mean peak virus titer of JKT27-087 differed significantly from the mean peak virus titers of the rest of the strains $(p<0.05)$. Similarly, the mean peak virus titers of G-I $(8.6 \pm 0.1)$ and G-III $(8.4 \pm 0.2)$ were not significantly different (one-way ANOVA, $\left.\mathrm{F}_{1}=1.1, p=0.3\right)$. Repeated measures ANOVA revealed a significant effect of strain on virus titer $\left(\mathrm{F}_{5}=2.7, p=0.02\right)$ and a significant time $\mathrm{x}$ strain interaction among six strains $\left(\mathrm{F}_{40}=2.4, p<0.001\right)$, and post-hoc Tukey-Kramer multiple comparison revealed only CH392 strain significantly different than JKT27-087 strain $(p=0.009)$. Virus titer for all strains declined after $3 \mathrm{dpi}$, corresponding to the observation of cytopathic effect in the Vero cells.

\section{Vero MOI $0.01(n=5)$}

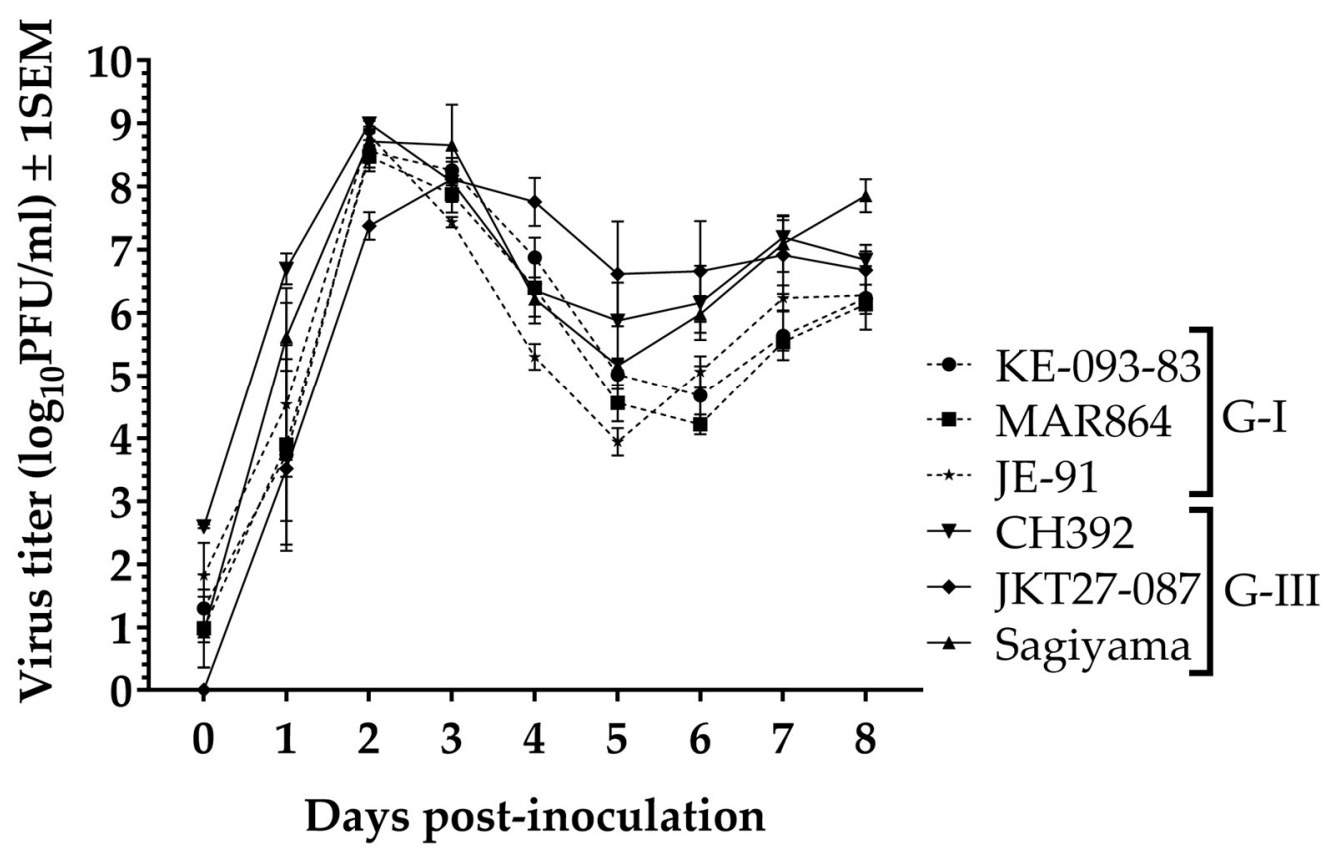

Figure 1. Growth curve of Japanese encephalitis virus G-I and G-III strains in Vero cells.

\subsection{Clinical Signs in Ducklings Inoculated with JEV}

None of the ducklings inoculated with JEV showed apparent signs of disease or distress. A mild elevation of body temperature (preinoculation body temperature range was $40.0-42.8^{\circ} \mathrm{C}$ ) on $1 \mathrm{dpi}$ was observed in ducklings inoculated with MAR864, CH392, JKT27-087, and Sagiyama strains, however general time effects on body temperature of virus-inoculated ducklings were hard to discern (Figure 2). The weight of ducklings increased linearly from about $100 \mathrm{~g}$ on 0 dpi to approximately $700 \mathrm{~g}$ in 22 days, and it demonstrates that the virus infection in ducklings did not reduce the daily gain in weight with the increase in age (Figure 3). Both the contact-control ducklings remained healthy and gained weight similar to the virus-inoculated ducklings. 
KE-093-83

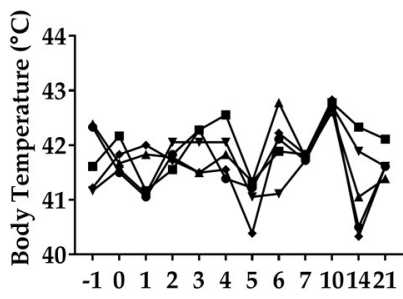

$\mathrm{CH} 392$

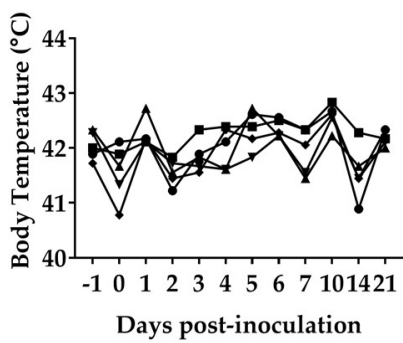

MAR864

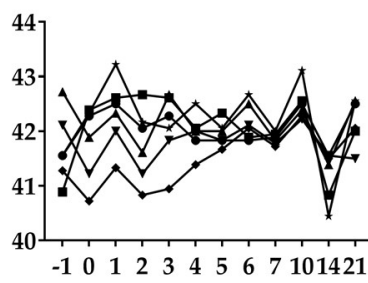

JKT27-087

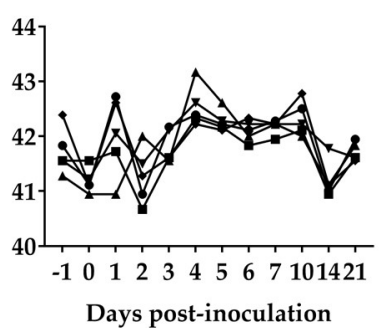

JE-91

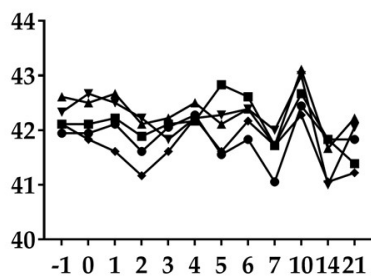

Sagiyama

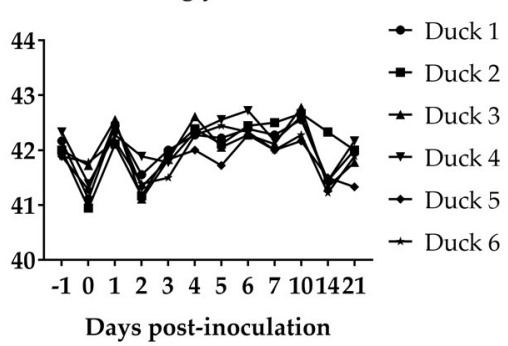

Figure 2. Body temperature in ducklings inoculated with Japanese encephalitis viruses. Duckling 6 for both MAR864 and Sagiyama groups were non-inoculated controls.

KE-093-83

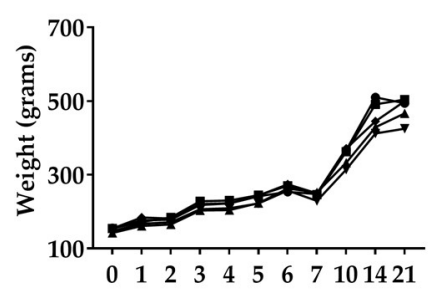

CH392

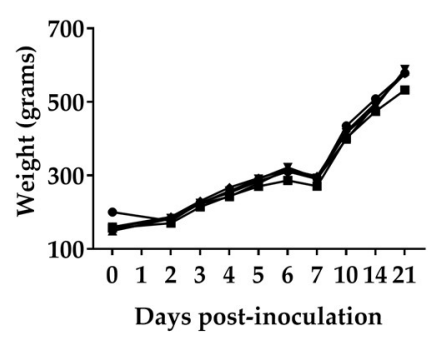

MAR864

JE-91
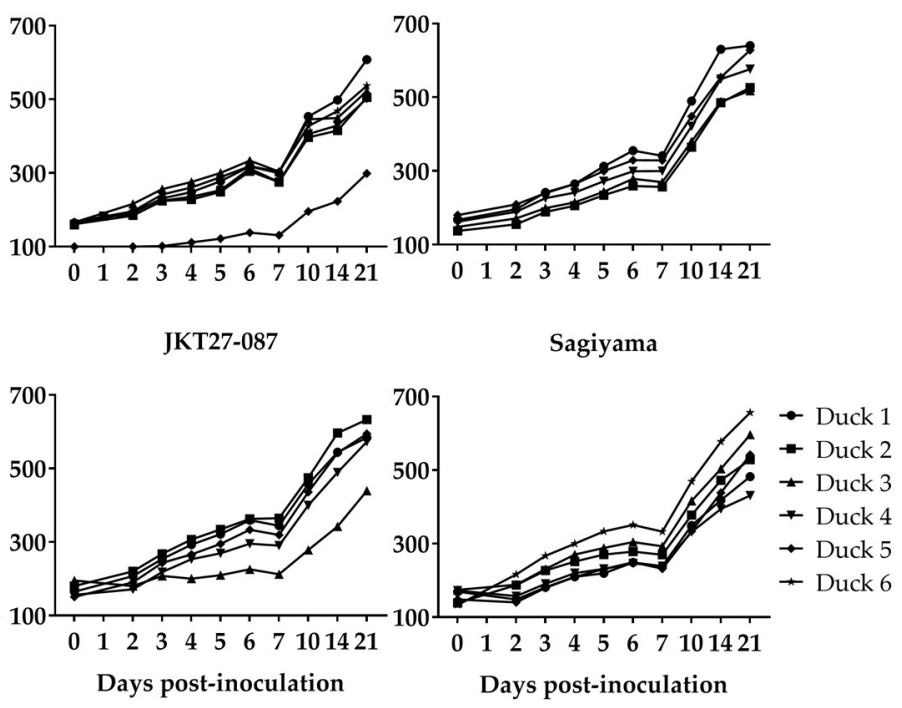

Figure 3. Body weight of ducklings inoculated with Japanese encephalitis viruses. Duckling 6 for both MAR864 and Sagiyama groups were non-inoculated controls.

\subsection{Replication of JEV in Ducklings}

The back-titrated dose of virus inoculated into ducklings ranged from 5.5 to $6.0 \log _{10} \mathrm{PFU} / \mathrm{mL}$. The viremia titer with individual strains (Figure 4) showed considerable consistency among the strains and between the genotypes in (i) duration to reach peak viremia titers, (ii) the peak titers, and (iii) the time viable virus is not detected in the serum. For all six strains and both genotypes, peak viremia was observed 2-3 dpi, and the mean peak viremia titers (mean $\pm 1 \mathrm{SE}, \log _{10} \mathrm{PFU} / \mathrm{mL}$ ) were: KE-093-83

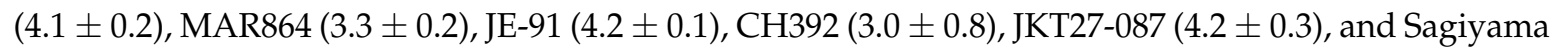
$(3.3 \pm 0.6)$. Similarly, the mean peak viremia titer (mean $\pm 1 \mathrm{SE}, \log _{10} \mathrm{PFU} / \mathrm{mL}$ ) in the ducklings for G-I and G-III were $3.9 \pm 0.2$ and $3.5 \pm 0.3$, respectively. The mean peak viremia titers of ducklings were neither significantly different among the six strains (oneway ANOVA, $\mathrm{F}_{5}=1.6, p=0.2$ ), nor were 
they significantly different between genotypes (Student's $t$-test, $\mathrm{t}_{28}=-1.02, p=0.3$ ). Virus was not detected after $3 \mathrm{dpi}$ in any of the ducklings, nor in either of the two non-inoculated control ducks.

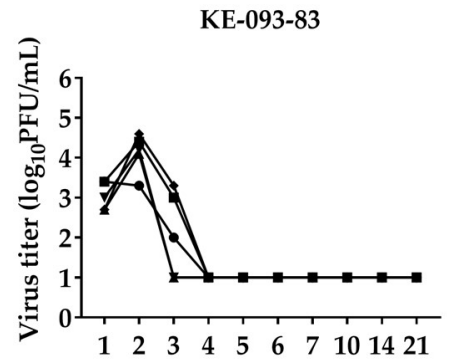

CH392

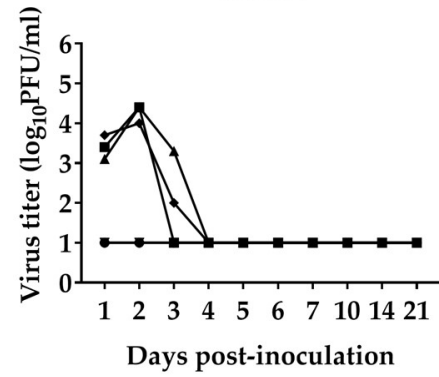

MAR864

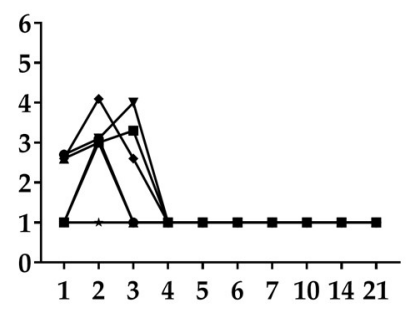

JKT27-087

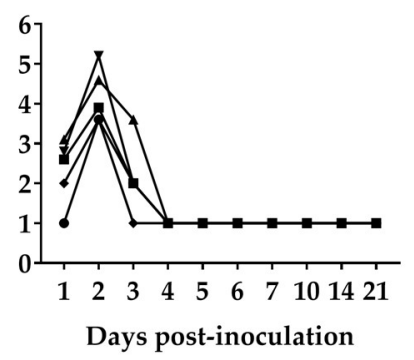

JE-91

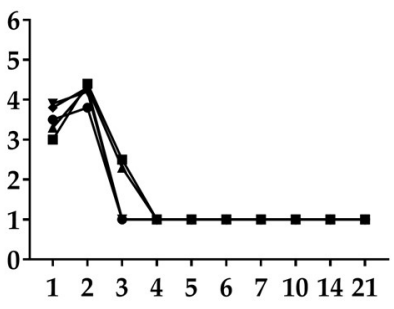

Sagiyama

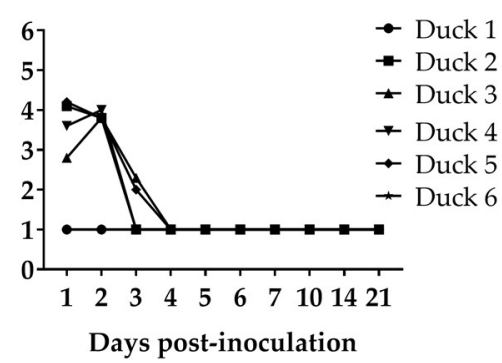

Figure 4. Viremia in ducklings inoculated with Japanese encephalitis viruses. Ducking 6 for both MAR864 and Sagiyama groups were non-inoculated controls. Virus titers $<2$ were below the limit of detection.

\subsection{Shedding of JEV from Ducklings}

Virus shedding in oral and cloacal secretions at and above the limit of detection $\left(2 \log _{10} \mathrm{PFU} / \mathrm{mL}\right)$ was observed on 3, 4, and 5 dpi (Figures 5 and 6). All 5 ducklings inoculated with KE-093-83 $\left(3.4 \pm 0.2, \log _{10} \mathrm{PFU} / \mathrm{mL}\right.$, mean $\left.\pm 1 \mathrm{SE}\right), \mathrm{JE}-91(2.5 \pm 0.2)$ and JKT27-087 (3.9 \pm 0.3$), 4$ of 5 ducklings inoculated with MAR864 (2.9 \pm 0.2$)$ and Sagiyama ( $3.7 \pm 0.1)$, and 2 of 5 ducklings inoculated with $\mathrm{CH} 392(3.6 \pm 0.2)$ shed viruses orally on 3 dpi. On 4 dpi, 1 out of 5 ducklings inoculated with KE-093-83 (2.0), JE-91 (3.2), and CH392 (3.5); 2 out 5 ducklings inoculated with Sagiyama (3.2 \pm 0.7 ); and 4 out 5 ducklings inoculated with MAR864 (4.0 \pm 0.3$)$ and JKT27-087 $(3.3 \pm 0.3)$ shed viruses orally. On 5 dpi, only a single duckling from KE-093-83, MAR864 and JKT27-087 shed viruses orally of titer 2.5, 3.1, and $3.4 \log _{10} \mathrm{PFU} / \mathrm{mL}$, respectively.

Regarding cloacal shedding of virus strains from ducklings, 1 out of 5 ducklings inoculated with CH392 (3.2), 2 out of 5 ducklings inoculated with KE-093-83 (3.4 \pm 0.9$)$ and MAR864 (2.2 \pm 0.2$)$, 3 out of 5 ducklings inoculated with JE-91(2.5 \pm 0.3$)$ and JKT27-087 (3.6 \pm 0.1$)$, and 4 out of 5 ducklings in Sagiyama ( $3.9 \pm 0.2)$ shed viruses through cloaca on 3 dpi. On 4 dpi, cloacal shedding of virus was observed in ducklings inoculated with KE-093-83 only, and that 2 out of 5 ducklings shed the virus at a titer of $3.4 \pm 0.7 \log _{10}$ PFU/mL. On $5 \mathrm{dpi}, 1$ out of 5 ducklings inoculated with MAR864 (2.8), JE-91 (2.3), and JKT27-087 (3.3), and 2 out of 5 ducklings inoculated with KE-093-83 (2.3 \pm 0.3$)$ shed viruses cloacally. 
Viruses 2019, 11, 32

9 of 16

KE-093-83

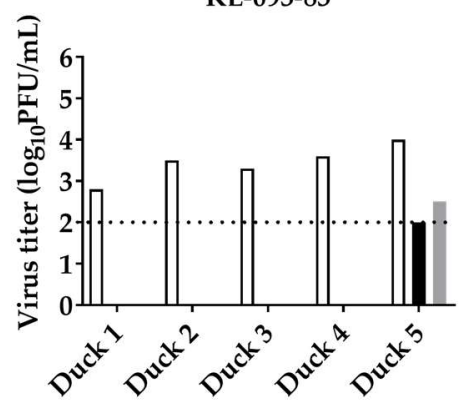

CH392

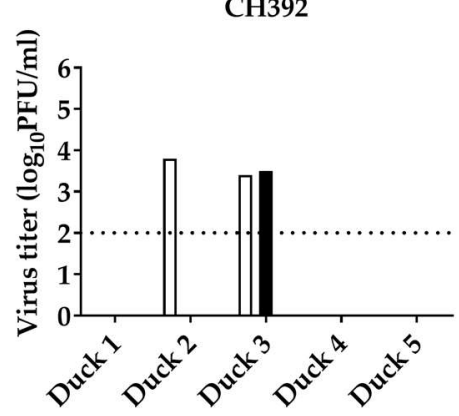

MAR864

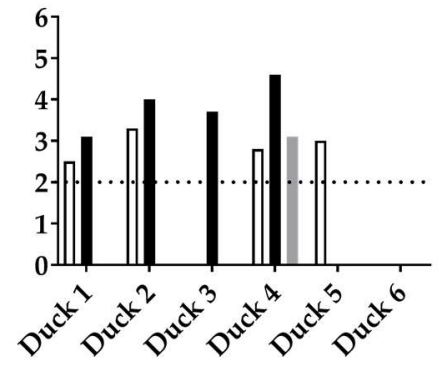

JKT27-087

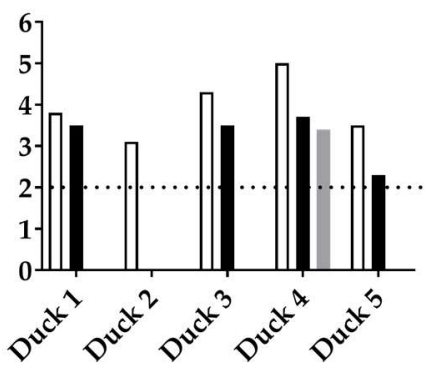

JE-91
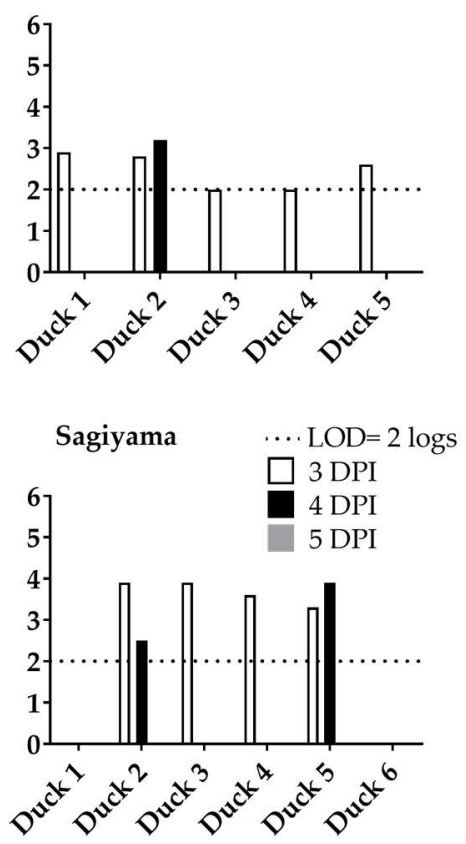

Figure 5. Oral shedding of Japanese encephalitis viruses from ducklings. Duckling 6 for both MAR864 and Sagiyama groups were non-inoculated controls.

KE-093-83

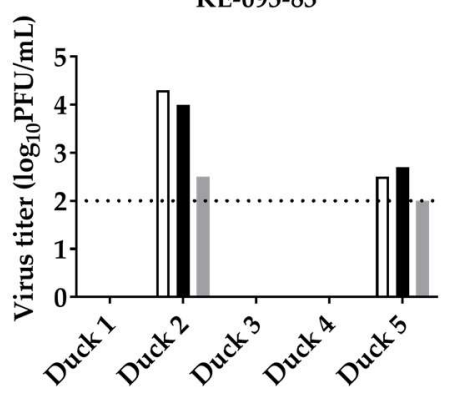

CH392

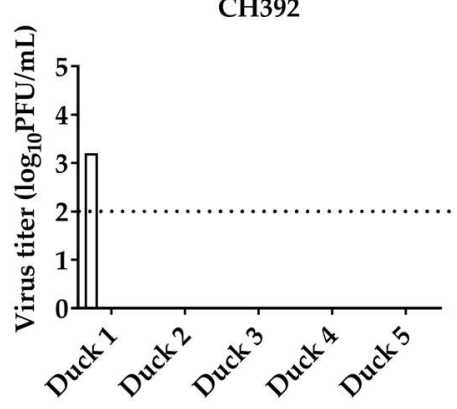

MAR864

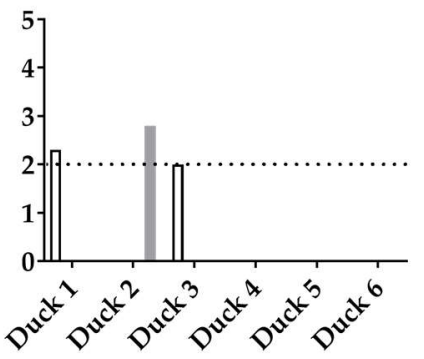

JKT27-087

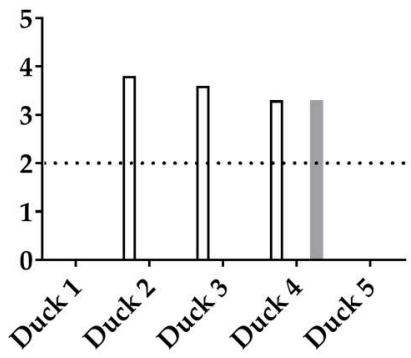

JE-91
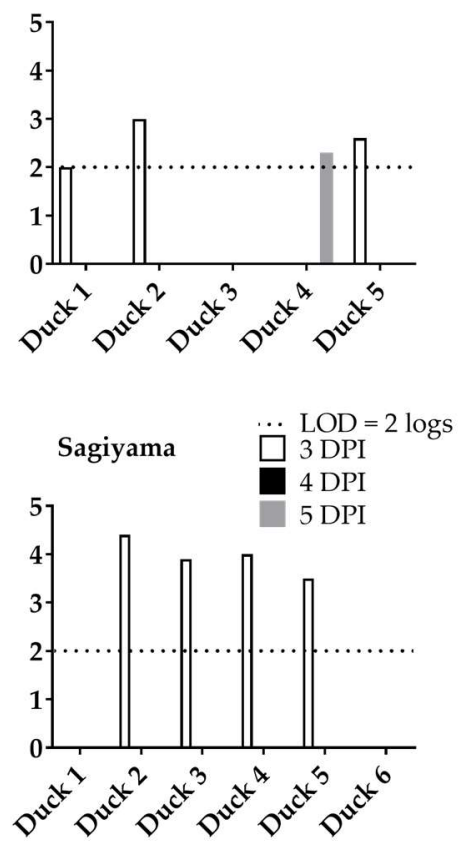

Figure 6. Cloacal shedding of Japanese encephalitis viruses from ducklings. Duckling 6 for both MAR864 and Sagiyama groups were non-inoculated controls. 


\subsection{Antibody Response to JEV in Ducklings}

Each duckling was seronegative $\left(\mathrm{PRNT}_{90}\right.$ titer $\left.<10\right)$ before inoculation with the viruses as demonstrated by the absence of virus-specific antibodies. All ducklings that were inoculated with virus, except one in the $\mathrm{CH} 392$ group, seroconverted by $7 \mathrm{dpi}$, and the neutralizing antibody titer (PRNT 90 increased by $21 \mathrm{dpi}$ (Table 2). Neither of the non-inoculated contact-control ducklings developed a detectable antibody response by $21 \mathrm{dpi}$, indicating a lack of contact transmission.

Table 2. Plaque Reduction Neutralization Test antibody titer in ducklings inoculated with Japanese encephalitis viruses ( $90 \%$ cut off).

\begin{tabular}{cccccccccc}
\hline & \multicolumn{3}{c}{ G-I } & & & \multicolumn{3}{c}{ G-III } \\
\hline Virus & Duck & 0 dpi & $\mathbf{7 ~ d p i}$ & $\mathbf{2 1}$ dpi & Virus & Duck & 0 dpi & 7 dpi & 21 dpi \\
\hline KE-093-83 & D1 & $<10$ & 40 & 320 & CH391 & D1 & $<10$ & $<10$ & 80 \\
& D2 & $<10$ & 20 & 320 & & D2 & $<10$ & 40 & 160 \\
& D3 & $<10$ & 40 & $\geq 640$ & & D3 & $<10$ & 40 & $\geq 320$ \\
& D4 & $<10$ & 20 & 80 & & D4 & $<10$ & 160 & 160 \\
& D5 & $<10$ & 80 & 320 & & D5 & $<10$ & 40 & 80 \\
MAR864 & D1 & $<10$ & 160 & 160 & JKT27-087 & D1 & $<10$ & 40 & $\geq 320$ \\
& D2 & $<10$ & 40 & 80 & & D2 & $<10$ & $\geq 320$ & $\geq 320$ \\
& D3 & $<10$ & 20 & 160 & & D3 & $<10$ & 80 & $\geq 320$ \\
& D4 & $<10$ & 10 & 160 & & D4 & $<10$ & 20 & $\geq 320$ \\
Control & D5 & $<10$ & 20 & 160 & & D5 & $<10$ & 40 & 80 \\
& DE-91 & $<10$ & $<10$ & $<10$ & Sagiyama & D1 & $<10$ & 40 & 80 \\
& D1 & $<10$ & 40 & 160 & & D2 & $<10$ & 20 & $\geq 320$ \\
& D2 & $<10$ & 80 & 80 & & D3 & $<10$ & 80 & $\geq 320$ \\
& D3 & $<10$ & 80 & 320 & & D4 & $<10$ & 160 & 80 \\
& D4 & $<10$ & 80 & 80 & & D5 & $<10$ & 40 & 160 \\
& D5 & $<10$ & 80 & 160 & Control & D6 & $<10$ & $<10$ & $<10$ \\
\hline
\end{tabular}

\subsection{Vector Competence and Extrinsic Incubation Period}

To test the hypothesis that G-I displaced G-III because it is more infectious for Cx. quinquefasciatus than G-III, competence of $C x$. quinquefasciatus for JEV G-I and G-III viruses was measured among 60 mosquitoes for each virus strain. The concentration of virus fed to the mosquitoes for each virus strain ranged from 5.1-5.9 $\log _{10} \mathrm{PFU} / \mathrm{mL}$ (Table 3). Cx. quinquefasciatus mosquitoes were found competent to transmit all six strains of JEV, but competence varied between JEV G-I and JEV G-III strains (Table 4). Interestingly, at $7 \mathrm{dpf}$, only G-I strains were detected in mosquito saliva (see Table 4 for $\%$ of mosquitoes in which JEV was detected) but not G-III strains as measured by immunofluorescence based-plaque assay in Vero cells, indicating a longer extrinsic incubation period (EIP) of JEV G-III (at least more than 7 days) than JEV G-I (as late as 7 days) in Cx. quinquefasciatus. By $14 \mathrm{dpf}$, all the six virus strains were detected in saliva. The findings supported our hypothesis, although dissemination percentage was not significantly different $\left(\mathrm{t}_{4}=-1.7, p=0.20\right)$, infection percentage $\left(\mathrm{t}_{4}=-4.8, p=0.009\right)$ and transmission percentage (2-tailed $p=0.0004)$ were significantly different between G-I and G-III on $7 \mathrm{dpf}$ in $C x$. quinquefasciatus. However, on $14 \mathrm{dpf}$, infection percentage $\left(\mathrm{t}_{4}=-1.3, p=0.30\right)$, dissemination percentage $\left(\mathrm{t}_{4}=-2.0, p=0.10\right)$, and transmission percentage (2-tailed $p=0.051$ ) were not significantly different between G-I and G-III. Although, the effect of genotype $x$ dpf on infection percentage $\left(\mathrm{F}_{3}=2.5, p=0.1\right)$ and dissemination percentage $\left(\mathrm{F}_{3}=2.5, p=0.1\right)$ was not significant, the effect was significant on transmission percentages $\left(\mathrm{F}_{3}=9.5, p=0.005\right)$. Our findings demonstrated JEV G-I is relatively better at infecting mosquitoes, disseminating through body parts of mosquitoes and being shed through saliva at an earlier time point. 
Table 3. Titration of the freshly harvested and the blood meal Japanese encephalitis virus strains.

\begin{tabular}{ccccc}
\hline Strain & Genotype & Type & PFU/mL & Log $_{\mathbf{1 0}}$ PFU/mL \\
\hline \multirow{2}{*}{ KE-093-83 } & \multirow{2}{*}{ I } & Fresh harvest & $4,100,000$ & 6.6 \\
& & Blood meal (1:1) & 750,000 & 5.9 \\
\hline \multirow{2}{*}{ MAR864 } & \multirow{2}{*}{ I } & Fresh harvest & $1,300,000$ & 6.1 \\
& \multirow{2}{*}{ JE-91 } & Blood meal (1:1) & 390,000 & 5.6 \\
\hline \multirow{2}{*}{ CH392 } & \multirow{2}{*}{ III } & Fresh harvest & $1,400,000$ & 6.1 \\
& & Blood meal (1:1) & 320,000 & 5.5 \\
\hline \multirow{2}{*}{ JKT27-087 } & \multirow{2}{*}{ III } & Fresh harvest & 100,000 & 6.0 \\
& & Blood meal (1:1) & 350,000 & 5.5 \\
\hline \multirow{2}{*}{ Sagiyama } & \multirow{2}{*}{ III } & Bresh harvest & 450,000 & 5.7 \\
& & Fresh harvest & $1,200,000$ & 5.1 \\
\hline
\end{tabular}

Table 4. Rates of infection, dissemination, transmission at 7- and 14-days post-feeding infectious blood meal to mosquitoes.

\begin{tabular}{cccccc}
\hline Virus Strain & Genotype & DPF & $\begin{array}{c}\text { Infection } \\
\mathbf{( \% )}\end{array}$ & $\begin{array}{c}\text { Dissemination } \\
\mathbf{( \% )}\end{array}$ & $\begin{array}{c}\text { Transmission } \\
\mathbf{( \% )}\end{array}$ \\
\hline \multirow{2}{*}{ KE-093-83 } & G-I & 7 & $56 / 60(93.3 \%)$ & $18 / 60(30 \%)$ & $1 / 60(1.6 \%)$ \\
& & 14 & $47 / 60(78.3 \%)$ & $33 / 60(55 \%)$ & $4 / 60(6.6 \%)$ \\
\hline \multirow{2}{*}{ MAR864 } & G-I & 7 & $56 / 60(93.3 \%)$ & $21 / 60(35 \%)$ & $8 / 60(13.3 \%)$ \\
& & 14 & $49 / 60(81.6 \%)$ & $11 / 60(18.3 \%)$ & $5 / 60(8.3 \%)$ \\
\hline \multirow{2}{*}{ JE-91 } & G-I & 7 & $47 / 60(78.3 \%)$ & $26 / 60(43.3 \%)$ & $3 / 60(5 \%)$ \\
& & 14 & $58 / 60(96.6 \%)$ & $43 / 60(71.6 \%)$ & $11 / 60(18.3 \%)$ \\
\hline \multirow{2}{*}{ CH392 } & G-III & 7 & $24 / 60(40 \%)$ & $15 / 60(25 \%)$ & $0 / 60(0 \%)$ \\
& & 14 & $13 / 60(21.6 \%)$ & $10 / 60(16.6 \%)$ & $3 / 60(5 \%)$ \\
\hline \multirow{2}{*}{ JKT27-087 } & G-III & 7 & $35 / 60(58.3 \%)$ & $5 / 60(8.3 \%)$ & $0 / 60(0 \%)$ \\
& & 14 & $42 / 60(70 \%)$ & $7 / 60(11.6 \%)$ & $2 / 60(3.3 \%)$ \\
\hline \multirow{2}{*}{ Sagiyama } & G-III & 7 & $32 / 60(53.3 \%)$ & $19 / 60(31.6 \%)$ & $0 / 60(0 \%)$ \\
& & 14 & $51 / 60(85 \%)$ & $13 / 60(21.6 \%)$ & $4 / 60(6.6 \%)$ \\
\hline
\end{tabular}

\section{Discussion}

Avian hosts are critical sources of JEV in endemic areas [5,41,42], and field data suggest ducks are infected by JEV [43,44]. Previous studies involving experimental infection in ducklings with JEV suggest that young ducks develop high magnitude viremia, compatible with serving as reservoir hosts [41]. Furthermore, it has been reported that domestic ducks infected with JEV can infect biting Culex species mosquitoes [45]. In the current study, we observed growth of virus in vitro and in vivo with all six strains of the JEV, three of each belonging to either JEV G-I or JEV G-III. All six strains of JEV reached peak titer of approximately $8-9 \log _{10} \mathrm{PFU} / \mathrm{mL}$ on $2-3$ dpi in Vero cells. Ducklings inoculated with freshly-grown viruses did not show signs of disease, but viremia was detected in serum obtained from all except 3 ducklings (two in CH392 group, one in Sagiyama group) on 1 to 3 dpi. Viremia ranged from 2-5.5 $\log _{10} \mathrm{PFU} / \mathrm{mL}$; previous studies indicated that only $10 \mathrm{PFU}$ of JEV is enough to infect mosquitoes $[46,47]$. There was no significant difference on the peak viremia titer among the six viruses tested in ducklings. Both JEV G-I and JEV G-III have been demonstrated to have similar pathogenic potential in mouse models, which is higher than representative strains of the other JEV genotypes [7]. Overall, we were not able to demonstrate a difference in fitness between viruses from G-I versus G-III based on replication in ducks, suggesting that differences in the ability to replicate in avian hosts is not the basis of genotype displacement. 
All but one duckling seroconverted by $7 \mathrm{dpi}$ and had higher antibody titer on $21 \mathrm{dpi}$, regardless of inoculated strain of JEV. Consistent with the demonstration that JEV G-III strain vaccine elicits higher antibody titer than JEV G-I strain vaccine in mouse model [7], our results indicate substantial seroconversion rate after inoculation with JEV G-III compared to JEV G-I on 7 dpi. JEV was also detected in oral and cloacal swabs obtained from ducklings inoculated with JEV G-I and JEV G-III, as has also been reported by Ricklin et al. [23] in pigs with the detection of RNA of JEV. Only infected ducklings demonstrated oral and/or cloacal shedding of JEV. Little is known about the significance, if any, of oral or cloacal shedding in the transmission of JEV. Although the current study was not specifically designed to test contact transmission, the lack of transmission to co-housed ducklings suggests that JEV is unlikely to be transmitted through the oral route in ducks.

$C x$. quinquefasciatus mosquitoes are known to be competent vectors for JEV in several areas of Asia [5,48], and the current study further confirmed the competence of this species for JEV. We observed higher infection, dissemination and salivary transmission with G-I than G-III. We did not measure infection, dissemination and transmission titer. Our study is consistent with higher infectivity previously reported for G-I than G-III for cultured mosquito cells [28] and Cx. quinquefasciatus in vivo [40]. JEV G-I also disseminated more rapidly than JEV G-III in Cx. quinquefasciatus. Since, JEV infection in Vero cells inoculated with 7 dpi saliva content of mosquitoes which were blood-fed with JEV G-III viruses was not detected, our study suggests a difference in extrinsic incubation period in mosquitoes as a responsible factor in genotype displacement. A shorter extrinsic incubation period of WNV 02 genotype strains of West Nile virus was reported to be the cause of WNV NY99 genotype displacement in the US [32,33]. Genotype displacement of WNV in the US [32,33], DENV-2 in the US [34], strain displacement in DENV-3 in Sri Lanka [35], clade displacement of DENV-2 in Nicaragua [36] demonstrated differences in replicative efficiency and transmission potential among circulating virus genotypes, strains, or clades, which is also applicable to JEV genotype displacement.

In addition to differences in EIP and host competence, other factors that may have contributed to genotype displacement include: (i) adaptation to the specific virus variants of mosquito species prevalent in different regions of Asia, (ii) the introduction of modernized farming practices including management of rice paddy fields and isolation of pig farms from urban environments, (iii) the implementation of concerted JEV immunization programs across many Asian countries, and (iv) the possible impact of climate change on migratory bird patterns and mosquito distribution. Although these represent possible mechanisms for displacement, evidence for those mechanisms are lacking.

Several caveats to the current study must be acknowledged. First, we utilized the Indian runner ducks in our study for several reasons: (i) they are a common domesticated breed of duck throughout Asia [49-52] and in endemic zones of JEV [17,53], (ii) previous studies from our laboratory confirmed them to be susceptible hosts for JEV, and (iii) ducklings have been detected with anti-JEV antibodies in JEV-endemic regions $[45,54,55]$. Second, we utilized $C x$. quinquefasciatus instead of known principle vector of JEV, $C x$. tritaeniorhynchus, due to unavailability of the latter vector in the US. The $C x$. quinquefasciatus used in this study have been maintained in a colony for several decades, and we understand vector competence for flaviviruses is impacted by a long-term colonization of mosquito vectors [56]. However, previous studies that utilized short-term colonized $C x$. quinquefasciatus [40] nonetheless showed a comparable vector competence, suggesting that our findings may reflect the actual dynamics of JEV in Cx. quinquefasciatus.

Future studies should include Culex tritaeniorhynchus from areas where displacement has been recorded, and evaluate vectorial capacity, extrinsic incubation period and virus titers in mosquitoes with single and mixed genotype infection. However, such mixed infections of JEV G-III and JEV G-I may not occur at a high rate (proportionally) in the field environment. In other words, competition may be demonstrated in the laboratory, but may be insignificant in the field since the frequency of mosquitoes being co-infected by both genotypes may not be sufficiently high to influence the predominant genotype. Host age is another feature that should be evaluated. The young ducklings 
used in the current study likely were not fully immunocompetent and differences among viral genotypes may have been masked at that young age.

The possibility of potential impact of the concerted immunization campaigns against JEV which may have occurred when G-III was pre-eminent, that is, G-III would have been affected by the vaccine leaving a void for G-I to fill. In this context, the timeframe in phylogenetic terms (temporal predictions for emergence/divergence) should be considered in future studies. It is possible that the presence of G-III as the predominant genotype for many years, coupled with vaccination using a G-III-based vaccine (SA-14-14-2) resulted in a high level of immunity to G-III in the community that was suboptimal in cross-protecting against G-I strains, facilitating establishment of G-I strains [57].

The broader impact of our study is that exploration of host-virus interaction by the utilization of ecologically relevant hosts and vectors will elucidate the mechanistic basis behind genotype emergence and displacement. Viral and host ecology are key components of disease emergence and spread, and this finding can extend into an exploration of other zoonotic viruses that co-circulate, co-evolve and show displacement events. Our study substantially lends empirical support to the potential importance of variation in EIP as an explanation for genotype displacement in JEV, and will allow theoreticians to formulate a mathematical model to explore the impact of this variation at a population level. Moreover, the widespread and close proximity of domestic ducks and humans throughout Asia suggests that if ducks indeed serve as an important reservoir for JEV, they may have an impact similar to pigs in amplifying the virus. Clearly, a one health approach to control of this pathogen will be critical to formulating effective control strategies.

Author Contributions: Conceptualization, A.K.K and R.A.B.; Methodology, A.K.K and R.A.B.; Investigation, A.K.K.; Data curation, A.K.K.; Formal Analysis, A.K.K.; Visualization, A.K.K.; Resources, R.A.B.; Project administration, R.A.B.; Writing-original draft preparation, A.K.K.; Writing-review and editing, A.K.K. and R.A.B.; Validation, R.A.B.; Supervision, R.A.B.; Funding acquisition, R.A.B.

Funding: This work was funded by the Animal Models Core at Colorado State University, and appreciation goes to USAID for providing a PhD fellowship to A.K.K.

Acknowledgments: We thank Paul Gordy and Airn Hartwig for the assistance in animal handling. We appreciate Gregory D. Ebel (Colorado State University) and his team for providing mosquitoes for the experiment. We also thank Robert B. Tesh (University of Texas Medical Branch) for providing the viruses for the experiment. We thank Kathryn A. Hanley (New Mexico State University) and Ernest A. Gould (Emergence des Pathologies Virales, Aix-Marseille University) for helpful comments.

Conflicts of Interest: The authors declare no conflict of interest. The funders had no role in the design of the study; in the collection, analyses, or interpretation of data; in the writing of the manuscript, or in the decision to publish the results.

\section{References}

1. Chambers, T.J.; Hahn, C.S.; Galler, R.; Rice, C.M. Flavivirus genome organization, expression, and replication. Annu. Rev. Microbiol. 1990, 44, 649-688. [CrossRef]

2. Lindenbach, B.D.; Rice, C.M. Molecular biology of flaviviruses. Adv. Virus Res. 2003, 59, 23-61. [PubMed]

3. Lord, J.S.; Gurley, E.S.; Pulliam, J.R. Rethinking Japanese Encephalitis Virus Transmission: A Framework for Implicating Host and Vector Species. PLoS Negl. Trop. Dis. 2015, 9, e0004074. [CrossRef] [PubMed]

4. Mackenzie, J.S.; Gubler, D.J.; Petersen, L.R. Emerging flaviviruses: The spread and resurgence of Japanese encephalitis, West Nile and dengue viruses. Nat. Med. 2004, 10 (Suppl. 12), S98-S109. [CrossRef] [PubMed]

5. Van den Hurk, A.F.; Ritchie, S.A.; Mackenzie, J.S. Ecology and geographical expansion of Japanese encephalitis virus. Annu. Rev. Entomol. 2009, 54, 17-35. [CrossRef]

6. Solomon, T.; Ni, H.; Beasley, D.W.; Ekkelenkamp, M.; Cardosa, M.J.; Barrett, A.D. Origin and evolution of Japanese encephalitis virus in southeast Asia. J. Virol. 2003, 77, 3091-3098. [CrossRef]

7. Beasley, D.W.; Li, L.; Suderman, M.T.; Guirakhoo, F.; Trent, D.W.; Monath, T.P.; Shope, R.E.; Barrett, A.D. Protection against Japanese encephalitis virus strains representing four genotypes by passive transfer of sera raised against ChimeriVax-JE experimental vaccine. Vaccine 2004, 22, 3722-3726. [CrossRef] [PubMed] 
8. Campbell, G.L.; Hills, S.L.; Fischer, M.; Jacobson, J.A.; Hoke, C.H.; Hombach, J.M.; Marfin, A.A.; Solomon, T.; Tsai, T.F.; Tsu, V.D.; et al. Estimated global incidence of Japanese encephalitis: A systematic review. Bull. World Health Organ. 2011, 89, 766-774. [CrossRef]

9. Pyke, A.T.; Williams, D.T.; Nisbet, D.J.; van den Hurk, A.F.; Taylor, C.T.; Johansen, C.A.; Macdonald, J.; Hall, R.A.; Simmons, R.J.; Mason, R.J.; et al. The appearance of a second genotype of Japanese encephalitis virus in the Australasian region. Am. J. Trop. Med. Hyg. 2001, 65, 747-753. [CrossRef]

10. Jeffries, C.L.; Walker, T. The Potential Use of Wolbachia-Based Mosquito Biocontrol Strategies for Japanese Encephalitis. PLoS Negl. Trop. Dis. 2015, 9, e0003576. [CrossRef] [PubMed]

11. Fischer, M.; Lindsey, N.; Staples, J.E.; Hills, S.; Centers for Disease, C.; Centers for Disease Control and Prevention. Japanese encephalitis vaccines: Recommendations of the Advisory Committee on Immunization Practices (ACIP). MMWR Recomm. Rep. 2010, 59, (RR-1). 1-27.

12. Erlanger, T.E.; Weiss, S.; Keiser, J.; Utzinger, J.; Wiedenmayer, K. Past, present, and future of Japanese encephalitis. Emerg. Infect. Dis. 2009, 15, 1-7. [CrossRef] [PubMed]

13. Han, N.; Adams, J.; Fang, W.; Liu, S.Q.; Rayner, S. Investigation of the genotype III to genotype I shift in Japanese encephalitis virus and the impact on human cases. Virol. Sin. 2015, 30, 277-289. [CrossRef]

14. Chen, W.R.; Tesh, R.B.; Rico-Hesse, R. Genetic variation of Japanese encephalitis virus in nature. J. Gen. Virol. 1990, 71, 2915-2922. [CrossRef] [PubMed]

15. Paranjpe, S.; Banerjee, K. Phylogenetic analysis of the envelope gene of Japanese encephalitis virus. Virus Res. 1996, 42, 107-117. [CrossRef]

16. Williams, D.T.; Wang, L.F.; Daniels, P.W.; Mackenzie, J.S. Molecular characterization of the first Australian isolate of Japanese encephalitis virus, the FU strain. J. Gen. Virol. 2000, 81, 2471-2480. [CrossRef]

17. Schuh, A.J.; Ward, M.J.; Brown, A.J.; Barrett, A.D. Phylogeography of Japanese encephalitis virus: Genotype is associated with climate. PLoS Negl. Trop. Dis. 2013, 7, e2411. [CrossRef]

18. Ali, A.; Igarashi, A. Antigenic and genetic variations among Japanese encephalitis virus strains belonging to genotype 1. Microbiol. Immunol. 1997, 41, 241-252. [CrossRef]

19. Wills, M.R.; Singh, B.K.; Debnath, N.C.; Barrett, A.D. Immunogenicity of wild-type and vaccine strains of Japanese encephalitis virus and the effect of haplotype restriction on murine immune responses. Vaccine 1993, 11, 761-766. [CrossRef]

20. Erra, E.O.; Askling, H.H.; Yoksan, S.; Rombo, L.; Riutta, J.; Vene, S.; Lindquist, L.; Vapalahti, O.; Kantele, A. Cross-protection elicited by primary and booster vaccinations against Japanese encephalitis: A two-year follow-up study. Vaccine 2013, 32, 119-123. [CrossRef] [PubMed]

21. Bonaparte, M.; Dweik, B.; Feroldi, E.; Meric, C.; Bouckenooghe, A.; Hildreth, S.; Hu, B.; Yoksan, S.; Boaz, M. Immune response to live-attenuated Japanese encephalitis vaccine (JE-CV) neutralizes Japanese encephalitis virus isolates from South-East Asia and India. BMC Infect. Dis. 2014, 14, 156. [CrossRef] [PubMed]

22. Ye, Q.; Xu, Y.P.; Zhang, Y.; Li, X.F.; Wang, H.J.; Liu, Z.Y.; Li, S.H.; Liu, L.; Zhao, H.; Nian, Q.G.; et al. Genotype-specific neutralization determinants in envelope protein: Implications for the improvement of Japanese encephalitis vaccine. J. Gen. Virol. 2015, 96, 2165-2175. [CrossRef] [PubMed]

23. Ricklin, M.E.; Garcia-Nicolas, O.; Brechbuhl, D.; Python, S.; Zumkehr, B.; Nougairede, A.; Charrel, R.N.; Posthaus, H.; Oevermann, A.; Summerfield, A. Vector-free transmission and persistence of Japanese encephalitis virus in pigs. Nat. Commun. 2016, 7, 10832. [CrossRef] [PubMed]

24. Ma, S.P.; Yoshida, Y.; Makino, Y.; Tadano, M.; Ono, T.; Ogawa, M. Short report: A major genotype of Japanese encephalitis virus currently circulating in Japan. Am. J. Trop. Med. Hyg. 2003, 69, 151-154. [CrossRef] [PubMed]

25. Nga, P.T.; del Carmen Parquet, M.; Cuong, V.D.; Ma, S.P.; Hasebe, F.; Inoue, S.; Makino, Y.; Takagi, M.; Nam, V.S.; Morita, K. Shift in Japanese encephalitis virus (JEV) genotype circulating in northern Vietnam: Implications for frequent introductions of JEV from Southeast Asia to East Asia. J. Gen. Virol. 2004, 85 Pt 6 , 1625-1631. [CrossRef]

26. Mohammed, M.A.; Galbraith, S.E.; Radford, A.D.; Dove, W.; Takasaki, T.; Kurane, I.; Solomon, T. Molecular phylogenetic and evolutionary analyses of Muar strain of Japanese encephalitis virus reveal it is the missing fifth genotype. Infect. Genet. Evol. 2011, 11, 855-862. [CrossRef]

27. Sarkar, A.; Taraphdar, D.; Mukhopadhyay, S.K.; Chakrabarti, S.; Chatterjee, S. Molecular evidence for the occurrence of Japanese encephalitis virus genotype I and III infection associated with acute encephalitis in patients of West Bengal, India, 2010. Virol. J. 2012, 9, 271. [CrossRef] 
28. Schuh, A.J.; Ward, M.J.; Leigh Brown, A.J.; Barrett, A.D. Dynamics of the emergence and establishment of a newly dominant genotype of Japanese encephalitis virus throughout Asia. J. Virol. 2014, 88, 4522-4532. [CrossRef]

29. Chen, Y.Y.; Fan, Y.C.; Tu, W.C.; Chang, R.Y.; Shih, C.C.; Lu, I.H.; Chien, M.S.; Lee, W.C.; Chen, T.H.; Chang, G.J.; et al. Japanese encephalitis virus genotype replacement, Taiwan, 2009-2010. Emerg. Infect. Dis. 2011, 17, 2354-2356. [CrossRef]

30. Pan, X.L.; Liu, H.; Wang, H.Y.; Fu, S.H.; Liu, H.Z.; Zhang, H.L.; Li, M.H.; Gao, X.Y.; Wang, J.L.; Sun, X.H.; et al. Emergence of genotype I of Japanese encephalitis virus as the dominant genotype in Asia. J. Virol. 2011, 85, 9847-9853. [CrossRef]

31. Fan, Y.C.; Lin, J.W.; Liao, S.Y.; Chen, J.M.; Chen, Y.Y.; Chiu, H.C.; Shih, C.C.; Chen, C.M.; Chang, R.Y.; King, C.C.; et al. Virulence of Japanese Encephalitis Virus Genotypes I and III, Taiwan. Emerg. Infect. Dis. 2017, 23, 1883-1886. [CrossRef]

32. Ebel, G.D.; Carricaburu, J.; Young, D.; Bernard, K.A.; Kramer, L.D. Genetic and phenotypic variation of West Nile virus in New York, 2000-2003. Am. J. Trop. Med. Hyg. 2004, 71, 493-500. [CrossRef] [PubMed]

33. Moudy, R.M.; Meola, M.A.; Morin, L.L.; Ebel, G.D.; Kramer, L.D. A newly emergent genotype of West Nile virus is transmitted earlier and more efficiently by Culex mosquitoes. Am. J. Trop. Med. Hyg. 2007, 77, 365-370. [CrossRef] [PubMed]

34. Armstrong, P.M.; Rico-Hesse, R. Differential susceptibility of Aedes aegypti to infection by the American and Southeast Asian genotypes of dengue type 2 virus. Vector Borne Zoonotic Dis. 2001, 1, 159-168. [CrossRef] [PubMed]

35. Hanley, K.A.; Nelson, J.T.; Schirtzinger, E.E.; Whitehead, S.S.; Hanson, C.T. Superior infectivity for mosquito vectors contributes to competitive displacement among strains of dengue virus. BMC Ecol. 2008, 8, 1. [CrossRef] [PubMed]

36. Quiner, C.A.; Parameswaran, P.; Ciota, A.T.; Ehrbar, D.J.; Dodson, B.L.; Schlesinger, S.; Kramer, L.D.; Harris, E. Increased replicative fitness of a dengue virus 2 clade in native mosquitoes: Potential contribution to a clade replacement event in Nicaragua. J. Virol. 2014, 88, 13125-13134. [CrossRef] [PubMed]

37. Do, L.P.; Bui, T.M.; Hasebe, F.; Morita, K.; Phan, N.T. Molecular epidemiology of Japanese encephalitis in northern Vietnam, 1964-2011: Genotype replacement. Virol. J. 2015, 12, 51. [CrossRef] [PubMed]

38. Nabeshima, T.; Loan, H.T.; Inoue, S.; Sumiyoshi, M.; Haruta, Y.; Nga, P.T.; Huoung, V.T.; del Carmen Parquet, M.; Hasebe, F.; Morita, K. Evidence of frequent introductions of Japanese encephalitis virus from south-east Asia and continental east Asia to Japan. J. Gen. Virol. 2009, 90 Pt 4, 827-832. [CrossRef]

39. Huang, J.H.; Lin, T.H.; Teng, H.J.; Su, C.L.; Tsai, K.H.; Lu, L.C.; Lin, C.; Yang, C.F.; Chang, S.F.; Liao, T.L.; et al. Molecular epidemiology of Japanese encephalitis virus, Taiwan. Emerg. Infect. Dis. 2010, 16, 876-878. [CrossRef]

40. Huang, Y.S.; Hettenbach, S.M.; Park, S.L.; Higgs, S.; Barrett, A.D.; Hsu, W.W.; Harbin, J.N.; Cohnstaedt, L.W.; Vanlandingham, D.L. Differential Infectivities among Different Japanese Encephalitis Virus Genotypes in Culex quinquefasciatus Mosquitoes. PLoS Negl. Trop. Dis. 2016, 10, e0005038. [CrossRef]

41. Cleton, N.B.; Bosco-Lauth, A.; Page, M.J.; Bowen, R.A. Age-related susceptibility to Japanese encephalitis virus in domestic ducklings and chicks. Am. J. Trop. Med. Hyg. 2014, 90, 242-246. [CrossRef] [PubMed]

42. Rosen, L. The natural history of Japanese encephalitis virus. Annu. Rev. Microbiol. 1986, 40, 395-414. [CrossRef] [PubMed]

43. Pant, G.R. A serological survey of pigs, horses, and ducks in Nepal for evidence of infection with Japanese encephalitis virus. Ann. N. Y. Acad. Sci. 2006, 1081, 124-129. [CrossRef] [PubMed]

44. Simpson, D.I.; Bowen, E.T.; Platt, G.S.; Way, H.; Smith, C.E.; Peto, S.; Kamath, S.; Lim Boo, L.; Lim Theong, W. Japanese encephalitis in Sarawak: Virus isolation and serology in a Land Dyak village. Trans. R. Soc. Trop. Med. Hyg. 1970, 64, 503-510. [CrossRef]

45. Dhanda, V.; Banerjee, K.; Deshmukh, P.K.; Ilkal, M.A. Experimental viraemia and transmission of Japanese encephalitis virus by mosquitoes in domestic ducks. Indian J. Med. Res. 1977, 66, 881-888. [PubMed]

46. Huang, Y.J.; Higgs, S.; Horne, K.M.; Vanlandingham, D.L. Flavivirus-mosquito interactions. Viruses 2014, 6, 4703-4730. [CrossRef]

47. Muangman, D.; Edelman, R.; Sullivan, M.J.; Gould, D.J. Experimental transmission of Japanese encephalitis virus by Culex fuscocephala. Am. J. Trop. Med. Hyg. 1972, 21, 482-486. [CrossRef] 
48. Nitatpattana, N.; Apiwathnasorn, C.; Barbazan, P.; Leemingsawat, S.; Yoksan, S.; Gonzalez, J.P. First isolation of Japanese encephalitis from Culex quinquefasciatus in Thailand. Southeast. Asian J. Trop. Med. Public Health 2005, 36, 875-878.

49. Olsen, B.; Munster, V.J.; Wallensten, A.; Waldenstrom, J.; Osterhaus, A.D.; Fouchier, R.A. Global patterns of influenza a virus in wild birds. Science 2006, 312, 384-388. [CrossRef]

50. Gilbert, M.; Xiao, X.; Chaitaweesub, P.; Kalpravidh, W.; Premashthira, S.; Boles, S.; Slingenbergh, J. Avian influenza, domestic ducks and rice agriculture in Thailand. Agric. Ecosyst. Environ. 2007, 119, 409-415. [CrossRef]

51. Gilbert, M.; Xiao, X.; Pfeiffer, D.U.; Epprecht, M.; Boles, S.; Czarnecki, C.; Chaitaweesub, P.; Kalpravidh, W.; Minh, P.Q.; Otte, M.J.; et al. Mapping H5N1 highly pathogenic avian influenza risk in Southeast Asia. Proc. Natl. Acad. Sci. USA 2008, 105, 4769-4774. [CrossRef]

52. Dhama, K.; Kumar, N.; Saminathan, M.; Tiwari, R.; Karthik, K.; Kumar, M.A.; Palanivelu, M.; Shabbir, M.Z.; Malik, Y.S.; Singh, R.K. Duck virus enteritis (duck plague)—A comprehensive update. Vet. Q. 2017, 37, 57-80. [CrossRef] [PubMed]

53. Miller, R.H.; Masuoka, P.; Klein, T.A.; Kim, H.C.; Somer, T.; Grieco, J. Ecological niche modeling to estimate the distribution of Japanese encephalitis virus in Asia. PLoS Negl. Trop. Dis. 2012, 6, e1678. [CrossRef] [PubMed]

54. Soman, R.S.; Rodrigues, F.M.; Guttikar, S.N.; Guru, P.Y. Experimental viraemia and transmission of Japanese encephalitis virus by mosquitoes in ardeid birds. Indian J. Med. Res. 1977, 66, 709-718. [PubMed]

55. Mackenzie, J.S.; Williams, D.T.; Smith, D.W. Japanese encephalitis virus: The geographic distribution, incidence, and spread of a virus with a propensity to emerge in new areas. Perspect. Med. Virol. 2006, 16, 201-268.

56. Lorenz, L.; Beaty, B.J.; Aitken, T.H.; Wallis, G.P.; Tabachnick, W.J. The effect of colonization upon aedes aegypti susceptibility to oral infection with yellow fever virus. Am. J. Trop. Med. Hyg. 1984, 33, 690-694. [CrossRef] [PubMed]

57. Ye, Q.; Li, X.F.; Zhao, H.; Deng, Y.Q.; Xu, Y.P.; Wang, H.Y.; Liang, G.D.; Qin, C.F. Reduction of neutralization antibody against heterologous circulating strains in adults immunized with Japanese encephalitis live vaccine. Hum. Vaccin Immunother. 2014, 10, 2704-2705. [CrossRef] 